\title{
Novel Low Spin Mixed Ligand Thiohydrazide Complexes of Iron(III): Synthesis, Spectral Characterization, Molecular Modeling, and Antibacterial Activity
}

\author{
Dolan Sengupta, ${ }^{1}$ Snigdha Gangopadhyay, ${ }^{1}$ Sanchita Goswami, ${ }^{2}$ Arnab Dutta, ${ }^{3}$ \\ Vikash Kumar, ${ }^{4}$ Sudipta De, ${ }^{1}$ and Pijush Kanti Gangopadhyay ${ }^{1}$ \\ ${ }^{1}$ Department of Chemistry, Presidency University (Former Presidency College), Kolkata 700073, India \\ ${ }^{2}$ Department of Chemistry, Calcutta University College of Science and Technology, Kolkata 700009, India \\ ${ }^{3}$ Pacific Northwest National Laboratory, 902 Battelle Boulevard, Richland, WA 99354, USA \\ ${ }^{4}$ Department of Polymer Science and Technology, Calcutta University College of Science and Technology, Kolkata 700009, India \\ Correspondence should be addressed to Snigdha Gangopadhyay; snigdhagangopadhyay@yahoo.com
}

Received 13 June 2014; Revised 12 August 2014; Accepted 15 August 2014; Published 17 September 2014

Academic Editor: Maurizio Peruzzini

Copyright (C) 2014 Dolan Sengupta et al. This is an open access article distributed under the Creative Commons Attribution License, which permits unrestricted use, distribution, and reproduction in any medium, provided the original work is properly cited.

\begin{abstract}
Mixed ligand complexes of $\mathrm{Fe}(\mathrm{III})$ with aromatic thiohydrazides of general composition $\left[\mathrm{Fe}(\mathrm{acac})(\mathrm{L})_{2}\right]$ have been synthesized and characterized (acac-acetylacetonate, $\mathrm{L}=$ bidentate uninegative aromatic thiohydrazide ligand, for example, thiobenzhydrazide, 2 hydroxythiobenzhydrazide, furan-2-thiohydrazide, and thiophen-2-thiohydrazide). The magnetic susceptibility data and the EPR spectra of these complexes suggested the formation of rhombically distorted low spin iron center $\left(\mathrm{d}^{5}\right)$ in octahedral environment, which was also supported by the UV-vis spectral data of the complexes. Biological studies of these complexes also indicated that the iron-thiohydrazido complexes have superior antibacterial properties compared to the corresponding ligands.
\end{abstract}

\section{Introduction}

Among the N, S bidentate donor ligands thiosemicarbazide and thiosemicarbazones received the largest attention due to their interesting chemical [1-5], analytical [6-10], and biological $[11,12]$ properties. These groups of ligands themselves are known for their antibacterial activity; however, this activity increases significantly when they coordinate to various metals, especially the first row transition metals $[13,14]$. Iron plays crucial roles in various physiological processes during cell growth. The effect of iron is more prominent for tumor cells, where they are more sensitive to iron deprivation compared to the normal cells [15]. Similar to the antibacterial activities, many studies have demonstrated that iron complexes have greater antitumor activity relative to the corresponding free ligands [16-18]. The interaction between thiosemicarbazoneiron(III) complexes with the cellular thiols or thiol functional group containing proteins is possibly the reason behind the superior cytotoxicity and antitumor activity [19].

Thiohydrazide ligands have the basic structural unit of $-\mathrm{C}(=\mathrm{S})-\mathrm{NH}-\mathrm{NH}_{2}$ and can function as excellent $\mathrm{N}, \mathrm{S}$ donor bidentate chelating ligands like thiosemicarbazides or thiosemicarbazones; however, they have simpler structures as they do not contain $\mathrm{N}^{4}$ nitrogen. The thiohydrazide ligands were also reported to have considerable antifungal and antibacterial activity, which were enhanced following the coordination with transition metal ions. In this communication, we have studied four different iron(III) complexes containing mixed ligands with the common formula $\left[\mathrm{Fe}(\mathrm{acac})(\mathrm{L})_{2}\right]$, where acac is acetylacetonate and $\mathrm{L}$ represents the aromatic thiohydrazide ligand. Thiobenzhydrazide (Htbh), o-hydroxythiobenzhydrazide (Hhtbh), furan-2-thiohydrazide (Hfth), and thiophen-2-thiohydrazide (Htth) are the four varieties of thiohydrazide ligands utilized 


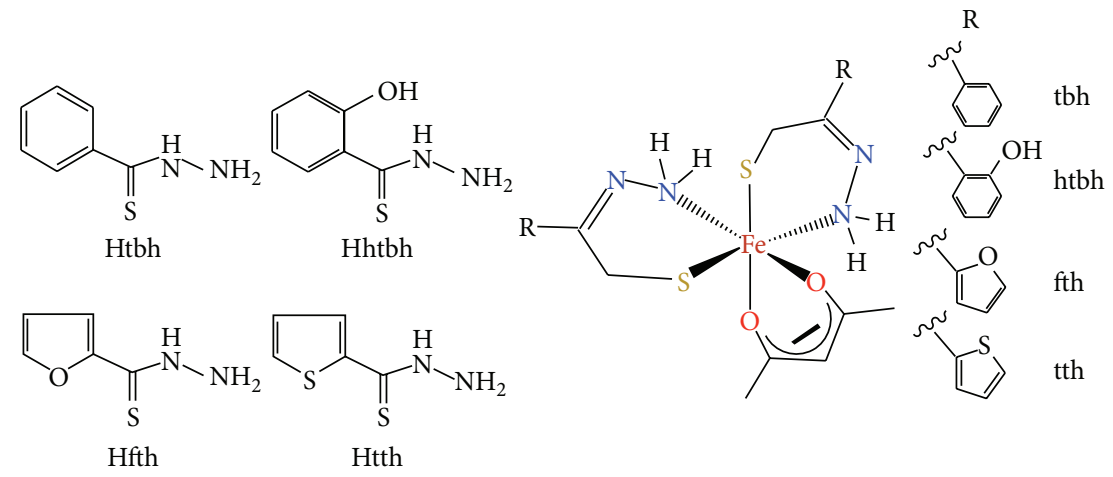

FIGURE 1: General structure of the thiohydrazide ligands and general structure of Fe(acac)(L) ${ }_{2}$ complexes.

in this study. The structure of the ligands and their respective complexes are shown in Figure 1.

We have characterized these complexes by the combination of various spectroscopic methods, magnetic measurements, and electrochemical techniques following the synthesis. The mode of coordination of ligands to iron(III) suggested from spectral studies has been corroborated with the results obtained by DFT calculation. Significant antibacterial activity was observed for these complexes during in vitro antibacterial study with Escherichia coli (E. coli).

\section{Experimental}

2.1. Materials and Methods. Anhydrous ferric chloride was purchased from E. Merck and was used as a source of iron(III). Thiohydrazide ligands were prepared following the procedure described earlier [20]. Tris-acetylacetonatoiron(III) $\left(\mathrm{Fe}(\mathrm{acac})_{3}\right)$ was used as the starting material for the synthesis of thiohydrazide complexes by ligand displacement and prepared by standard method [21]. E. coli (K12) strain was obtained from the Department of Botany, Presidency University, Kolkata. Fresh cultures were prepared on MacConkey Agar media (Himedia, India). All solvents used were purified according to the standard methods. All other chemicals were of reagent grade and used without further purification.

\subsection{Synthesis of Complexes}

2.2.1. Synthesis of Iron(III) Complex of Thiobenzhydrazide $\mathrm{Fe}(\mathrm{acac})(\mathrm{tbh})_{2}$. A methanolic solution of $176 \mathrm{mg}(0.5 \mathrm{mmol})$ $\mathrm{Fe}(\mathrm{acac})_{3}$ was added dropwise to a methanolic solution of $228 \mathrm{mg}(1.5 \mathrm{mmol})$ thiobenzhydrazide and the mixture was stirred for three hours. The volume of the solution was reduced under vacuum and kept for 48 hours. The resulting solid was filtered washed with methanol and dried under vacuum. Anal. Calc. for $\mathrm{C}_{19} \mathrm{H}_{21} \mathrm{~N}_{4} \mathrm{~S}_{2} \mathrm{O}_{2}$ Fe: C, 50.00; $\mathrm{H}, 4.60$; N, 12.30. Found; C, 50.11; H, 4.70; N, 12.22. UVvis spectrum: $\lambda_{\max }$ (in benzene) $881,585.2,311.5 \mathrm{~nm}$. IR Bands $v_{\mathrm{C}=\mathrm{S}} 1155 \mathrm{~cm}^{-1}, 1060 \mathrm{~cm}^{-1}, 820 \mathrm{~cm}^{-1} ; v_{\mathrm{C}-\mathrm{N}} 1580 \mathrm{~cm}^{-1}$, $1470 \mathrm{~cm}^{-1} ; \nu_{\mathrm{Fe}-\mathrm{N}} 470 \mathrm{~cm}^{-1} ; \nu_{\mathrm{Fe}-\mathrm{S}} 380 \mathrm{~cm}^{-1} ; \nu_{\mathrm{Fe}-\mathrm{O}} 655 \mathrm{~cm}^{-1}$, $530 \mathrm{~cm}^{-1}$. Magnetic moment $\left(\mu_{\mathrm{eff}}\right)=1.71 \mathrm{~B} . \mathrm{M}$. at $300 \mathrm{~K}$.
2.2.2. Synthesis of Iron(III) Complex of o-Hydroxythiobenzhydrazide $\mathrm{Fe}(\mathrm{acac})(\mathrm{htbh})_{2}$. The complex is prepared in a similar procedure to that of $\mathrm{Fe}(\mathrm{acac})(\mathrm{tbh})_{2}$. Anal. Calc. for $\mathrm{C}_{19} \mathrm{H}_{21} \mathrm{~N}_{4} \mathrm{~S}_{2} \mathrm{O}_{4} \mathrm{Fe}: \mathrm{C}, 46.50 ; \mathrm{H}, 4.29 ; \mathrm{N}, 11.42$. Found; C, 46.23; H, 4.27; $\mathrm{N}, 11.43$. UV-vis spectrum: $\lambda_{\max }$ (in benzene) $899,592.40,546,376$, and $319 \mathrm{~nm}$. IR Bands $v_{\mathrm{C}=\mathrm{S}}$ $1155 \mathrm{~cm}^{-1}, 1060 \mathrm{~cm}^{-1}, 820 \mathrm{~cm}^{-1} ; v_{\mathrm{C}-\mathrm{N}} 1585 \mathrm{~cm}^{-1}, 1480 \mathrm{~cm}^{-1}$; $\nu_{\mathrm{Fe}-\mathrm{N}} 470 \mathrm{~cm}^{-1} ; \nu_{\mathrm{Fe}-\mathrm{S}} 370 \mathrm{~cm}^{-1} ; \nu_{\mathrm{Fe}-\mathrm{O}} 660 \mathrm{~cm}^{-1}, 535 \mathrm{~cm}^{-1}$. Magnetic moment $\left(\mu_{\text {eff }}\right)=1.73$ B.M. at $300 \mathrm{~K}$.

2.2.3. Synthesis of Iron(III) Complexes of Furan-2-thiohydrazide $\mathrm{Fe}(\mathrm{acac})(\mathrm{fth})_{2}$. The complex is prepared in a similar procedure to that of $\mathrm{Fe}(\mathrm{acac})(\mathrm{tbh})_{2}$. Anal. Calc. for $\mathrm{C}_{15} \mathrm{H}_{17} \mathrm{~N}_{4} \mathrm{~S}_{2} \mathrm{O}_{4} \mathrm{Fe}: \mathrm{C}, 41.10 ; \mathrm{H}, 3.89 ; \mathrm{N}, 12.78$. Found; C, 41.21; H, 3.92; N, 12.75. UV-vis spectrum: $\lambda_{\text {max }}$ (in benzene) $868.50,617.20 \mathrm{~nm}$. IR Bands $\nu_{\mathrm{C}=\mathrm{S}} 1230 \mathrm{~cm}^{-1}, 1090 \mathrm{~cm}^{-1}$, $810 \mathrm{~cm}^{-1} ; \nu_{\mathrm{C}-\mathrm{N}} 1550 \mathrm{~cm}^{-1} ; \nu_{\mathrm{Fe}-\mathrm{N}} 490 \mathrm{~cm}^{-1} ; \nu_{\mathrm{Fe}-\mathrm{S}} 370 \mathrm{~cm}^{-1}$; $\nu_{\mathrm{Fe}-\mathrm{O}} 680 \mathrm{~cm}^{-1}$. Magnetic moment $\left(\mu_{\mathrm{eff}}\right)=1.76$ B.M. at $300 \mathrm{~K}$.

2.2.4. Synthesis of Iron(III) Complex of Thiophen-2-thiohydrazide $\mathrm{Fe}(\mathrm{acac})(\mathrm{tth})_{2}$. The complex is prepared in a similar procedure to that of $\mathrm{Fe}(a \mathrm{cac})(\mathrm{tbh})_{2}$. Anal. Calc. for $\mathrm{C}_{15} \mathrm{H}_{17} \mathrm{~N}_{4} \mathrm{~S}_{4} \mathrm{O}_{2} \mathrm{Fe}: \mathrm{C}, 36.57 ; \mathrm{H}, 2.11 ; \mathrm{N}, 8.87$. Found; C, 36.51; $\mathrm{H}, 2.12 ; \mathrm{N}, 8.89$. UV-vis spectrum: $\lambda_{\max }$ (in benzene) 873.50, 598.80, 414.80, and $343.60 \mathrm{~nm}$, IR Bands $\nu_{\mathrm{C}=\mathrm{S}} 1260 \mathrm{~cm}^{-1}$, $715 \mathrm{~cm}^{-1} ; \nu_{\mathrm{C}-\mathrm{N}} 1510 \mathrm{~cm}^{-1} ; \nu_{\mathrm{Fe}-\mathrm{N}} 470 \mathrm{~cm}^{-1} ; \nu_{\mathrm{Fe}-\mathrm{S}} 370 \mathrm{~cm}^{-1}$; $\nu_{\mathrm{Fe}-\mathrm{O}} 660 \mathrm{~cm}^{-1}$. Magnetic moment $\left(\mu_{\mathrm{eff}}\right)=1.70$ B.M. at $300 \mathrm{~K}$.

2.3. Physical Measurements. Elemental microanalyses (C, $\mathrm{H}$, $\mathrm{N}, \mathrm{S}$ ) were done at Indian Association of Cultivation Sciences (IACS) facility, Kolkata, using 2400 series II Perkin Elmer, CHNS analyzer. Magnetic susceptibility was measured with a MAGWAY MFG Mk 1 (Sherwood Scientific Ltd., UK). Electronic spectra were recorded on a Hitachi $3210 \mathrm{UV}$ visible spectrophotometer. IR spectra were obtained on a Unicam300S spectrophotometer $\left(4000-300 \mathrm{~cm}^{-1}\right)$ and the samples were prepared as $\mathrm{KBr}$ pellets. Continuous wave electron paramagnetic resonance (CW-EPR) spectra were recorded at Bruker X-band EPR instrument in dimethyl sulfoxide (DMSO) solution (99.5\%, Sigma-Aldrich) at $10 \mathrm{~K}$ temperature using liquid helium. Sample concentrations were 
0.5-0.6 $\mathrm{mM}$ and were degassed with argon flow for 15 minutes prior to the experiment. EasySpin software was used to simulate the EPR data [22]. Electrochemical measurements were performed with a EG\&G Potentiostat model 263A instrument using standard three-electrode set-up, where a platinum working electrode, a platinum wire auxiliary electrode, and an $\mathrm{Ag} / \mathrm{AgCl}$ (saturated $\mathrm{KCl}$ ) reference electrode were used. All cyclic voltammetric experiments were performed under a nitrogen atmosphere in distilled DMSO and $\mathrm{CH}_{2} \mathrm{Cl}_{2}$ solution. Tertiary butyl ammonium perchlorate (TBAP) was used as the electrolyte during the experiments. Cyclic voltammometric data were collected at $298 \mathrm{~K}$ and are uncorrected for junction potential.

2.4. Antibacterial Activity. A wild variety of E. coli strains were utilized for this study. E. coli strain was maintained in MacConkey agar medium. MUG Muller Hinton broth was inoculated by a single colony of $E$. coli from the slant culture. Liquid broth culture was incubated at $37^{\circ} \mathrm{C}$ for 6 hours in a BOD incubator to attain log phase of growth. Standard solutions of thiohydrazide complexes of iron(III) are prepared in 1:1 DMSO: water mixture and requisite volumes of these solutions were added to $10 \mathrm{~mL}$ of liquid MUG Mueller Hinton broth kept in culture tubes.

The solutions were sterilized and inoculated with $0.2 \mathrm{~mL}$ of the 6-hour-old E. coli broth culture. These solutions were incubated at $37^{\circ} \mathrm{C}$ for 24 hours in the BOD incubator. 24hour-old cultures were serially diluted and poured on Petri dishes containing MacConkey agar medium. After 24 hours incubation at $37^{\circ} \mathrm{C}$ colonies were counted following the standard procedure $[23,24]$.

\section{Results and Discussion}

All the synthesized iron(III) thiohydrazide complexes were dark and highly soluble in dimethyl sulfoxide (DMSO), N,N' dimethyl formamide (DMF), and acetonitrile. However they were only sparingly soluble in organic protic solvents like methanol and ethanol. All the compounds were paramagnetic in nature exhibiting the presence of one unpaired electron (observed magnetic moment $\left(\mu_{\text {eff }}\right) \sim 1.70$ B.M. at room temperature). Elemental analyses of the complexes demonstrated the presence of $1: 2$ metal to thiohydrazide ligand ratio and suggested the formation of $\mathrm{Fe}(\mathrm{acac})(\mathrm{L})_{2}$ type of compound where $\mathrm{L}$ is the thiohydrazide derived ligand.

3.1. Synthesis. At first attempts were made to prepare homoleptic thiohydrazidoiron(III) complexes by directly adding ethanolic solution of iron(III) chloride to the thiohydrazide ligands but the desired tristhiohydrazido compound could not be isolated. We were able to grow crystal of the product from the reaction between $\mathrm{FeCl}_{3}$ and thiobenzhydrazide. The X-ray crystallographic data showed the product to be $3,3^{\prime}$-diphenylthiophen, without the presence of any iron atom. This compound presumably formed as a result of iron(III) mediated oxidation of the ligand. The standard reduction potential value of the $\mathrm{Fe}^{3+/ 2+}$ changes from $0.77 \mathrm{~V}$ to $-0.42 \mathrm{~V}$ (versus SHE) when it is coordinated to acetylacetonato (acac) ligand in DMF medium [25]. Thus the system loses its oxidizing property when $\mathrm{Fe}(\mathrm{acac})_{3}$ is used as the precursor and the chances of metal mediated ligand oxidation is minimized. However, all the three acac ligands could not be replaced by thiohydrazide even when ten-time excess of the ligand was used. The strong bonding between acac and Fe(III) through both $\sigma$-donation and $\pi$-back bonding is possibly the reason behind it.

3.2. Electronic Spectra. The electronic spectra of different iron thiohydrazide complexes were examined in various organic solvents like acetonitrile, acetone, benzene, and DMSO. The weak bands observed in the region 900-910 nm were attributed to d-d transition [26]. The nature of this particular band was further examined by DFT studies (vide infra). The bands near $600-580 \mathrm{~nm}$ and $380-360 \mathrm{~nm}$ were assigned to ligand to metal charge transfer (LMCT) bands. The intensity and marked dependence of the bands with solvent are consistent with the charge transfer nature of the bands. The bands in the region $300-310 \mathrm{~nm}$ are attributed to aromatic ligand-ligand charge transfer (LLCT) band.

3.3. Infrared Spectra. The IR spectra of the iron(III) thiohydrazide complexes were compared with the free ligands to have an insight into the binding patterns of the ligand molecules. For all the complexes, the backbone vibrational signals such as $\mathrm{C}-\mathrm{C}$ and $\mathrm{C}-\mathrm{H}$ stretchings of the benzene ring, aromatic out of plane $\mathrm{C}-\mathrm{H}$ bending, aromatic in plane $\mathrm{C}-\mathrm{H}$ bending, aliphatic hydrizido $\mathrm{N}-\mathrm{N}$ stretching, and $\mathrm{C}-$ $\mathrm{N}-\mathrm{N}$ backbone bending $(\beta(\mathrm{C}-\mathrm{N}-\mathrm{N}))$ remained unaltered following the metalation, indicating the robust nature of the backbone during the synthesis [20]. However, the $\mathrm{C}-\mathrm{N}$ stretching band $(\nu(\mathrm{C}-\mathrm{N}))$, which occurs in the range of 1580 $1530 \mathrm{~cm}^{-1}$ in the ligands [20], shifted to higher frequency in the complexes suggesting partial double bond character in the $\mathrm{C}-\mathrm{N}$ bond. On the other hand, the $v(\mathrm{C}=\mathrm{S})$ stretching vibration shifted to a lower frequency in the iron complexes indicating decrease of the bond order for $\mathrm{C}=\mathrm{S}$ bond during metal coordination. These observations suggested that the ligands undergo thioenolization before ligation and they are coordinated to iron via thiol sulphur. The IR data also showed the presence of $\mathrm{Fe}-\mathrm{N}$ and $\mathrm{Fe}-\mathrm{S}$ bands around the regions $490-470 \mathrm{~cm}^{-1}$ [27] and 380-370 $\mathrm{cm}^{-1}$ [28], respectively, supporting the metal-thiohydrazido binding pattern (Figure 1). It is important to note that these bands were absent in both free ligand and precursor Fe complex. In addition to those bands, the metal oxygen band ( $\nu \mathrm{Fe}-\mathrm{O}$ ) was also observed for the complexes, similar to the synthon $\mathrm{Fe}(\mathrm{acac})_{3}$, in the region $680-655 \mathrm{~cm}^{-1}$, indicating the presence of $\mathrm{Fe}(\mathrm{acac})$ binding in the mixed ligand complexes [29]. The bending mode of vibration for terminal amine of the hydrazine group $\left(\beta \mathrm{NH}_{2}\right)$ was observed near $1600 \mathrm{~cm}^{-1}$ in free ligands and these bands shifted towards higher frequency in the complexes, indicating complexation through hydrazinic $-\mathrm{NH}_{2}$ group. The $\mathrm{C}=\mathrm{O}$ stretching frequency $(\nu \mathrm{C}=\mathrm{O})$ was observed in the range $1580-1570$ and $1530-1525 \mathrm{~cm}^{-1}$ region for both the complexes and $\mathrm{Fe}(\mathrm{acac})_{3}$ [29]. However, the intensity 
TABLE 1: EPR parameters of acetylacetonatobisthiohydazidoiron(III) complexes.

\begin{tabular}{lccccccc}
\hline Compound & $g_{x}$ & $g_{y}$ & $g_{z}$ & $V / \lambda$ & $\Delta / \lambda$ & $V / \Delta$ & $g_{\max }-g_{\min }$ \\
\hline$\left[\mathrm{Fe}(\mathrm{acac})(\mathrm{tbh})_{2}\right]$ & 2.022 & 2.13 & 2.165 & 15.37 & 12.83 & 1.2 & 0.143 \\
{$\left[\mathrm{Fe}(\mathrm{acac})(\mathrm{htbh})_{2}\right]$} & 2.005 & 2.165 & 2.185 & 12.53 & 7.90 & 1.59 & 0.180 \\
{$\left[\mathrm{Fe}(\mathrm{acac})(\mathrm{fth})_{2}\right]$} & 2.002 & 2.12 & 2.18 & 12.38 & 12.26 & 1.01 & 0.178 \\
{$\left[\mathrm{Fe}(\mathrm{acac})(\mathrm{tth})_{2}\right]$} & 2.001 & 2.13 & 2.175 & 12.71 & 10.97 & 1.16 & 0.174 \\
\hline
\end{tabular}

$\Delta$ : tetragonal splitting parameter; $V$ : rhombic splitting parameter; $\lambda$ : spin-orbit coupling constant. Rhombic distortion $V / \lambda=g_{x} /\left(g_{z}+g_{y}\right)+g_{y} /\left(g_{z}-g_{x}\right)$.

TABLE 2: Cyclic voltammetric data of iron thiohydrazide complexes.

\begin{tabular}{|c|c|c|c|c|c|}
\hline Compound & $E_{\mathrm{pa}}(\mathrm{V})$ & $E_{\mathrm{pc}}(\mathrm{V})$ & $E_{1 / 2}(\mathrm{~V})$ & $\Delta E_{p}(\mathrm{~V})$ & $I_{\mathrm{pa}} / I_{\mathrm{pc}}$ \\
\hline $\mathrm{Fe}(\mathrm{acac})(\mathrm{tbh})_{2}$ & -0.7927 & $\begin{array}{c}-0.6148 \\
-1.06\end{array}$ & -0.704 & 177.9 & 0.09 \\
\hline $\mathrm{Fe}(\mathrm{acac})(\mathrm{htbh})_{2}$ & -0.6715 & -0.5907 & -0.6311 & 80.8 & 0.23 \\
\hline $\mathrm{Fe}(\mathrm{acac})(\mathrm{fth})_{2}$ & -0.5117 & $\begin{array}{c}-0.6077 \\
-1.04\end{array}$ & -0.5597 & 96 & 0.88 \\
\hline $\mathrm{Fe}(\mathrm{acac})(\mathrm{tth})_{2}$ & -0.3326 & $\begin{array}{l}-0.2436 \\
-0.5574\end{array}$ & -0.2881 & 89 & 1.3 \\
\hline
\end{tabular}

of the bands was lower for the mixed ligand complexes compared to the precursor $\mathrm{Fe}(\mathrm{acac})_{3}$ as two acetylacetonato groups were substituted by the thiohydrazide ligands during complexation.

3.4. EPR Spectra. Tris-acetylacetonatoiron(III) complex was used as the precursor for iron during this study, which is a high spin $d^{5}$ complex $(S=5 / 2)$. During this study, we observe that all the four varieties of thiohydrazide ligands were able to replace two of those acetylacetonato ligands to produce mixed ligand (acetylacetonato)(bis-thiohydrazido)iron(III) complex. The magnetic susceptibility data for all the complexes indicated presence of only one unpaired electron (S $=1 / 2$ ) with the observed magnetic moment $\left(\mu_{\mathrm{eff}}\right) \sim 1.70$ B.M. $\left(\mu_{\mathrm{eff}}=\sqrt{[n(n+2)]}\right.$ B.M., $n=1$ in this case $)$. To monitor the paramagnetic properties of these complexes in detail, X-band EPR spectra for all the complexes were collected in DMSO solution at $10 \mathrm{~K}$. The EPR spectra are depicted in Figure 2 and the simulated spectral parameters are shown in Table 1.

The EPR spectra of the complexes reveal that the replacement of four $\mathrm{O}$-donor atoms by two $\mathrm{S}$ and two $\mathrm{N}$-donors converts it to a low spin complex as apparent from the $g$ values in range of 2.001-2.185. Small spread of the $g$-values appears to be characteristic of low spin Fe(III) centers with coordinated $\mathrm{N}_{2} \mathrm{~S}_{2}$ from two thiohydrazido ligand and two $\mathrm{O}$ from acetylacetonato group. The high value of $V / \lambda$ indicates large rhombic distortion. The $V / \lambda$ values are large for all the complexes, suggesting high rhombicity. This may be further confirmed by $V / \Delta$ values that are higher than $2 / 3 r d[30,31]$. Thus the possibility of tetragonal structure is eliminated. All the complexes exhibit $g_{\max }-g_{\min }$ values in the range of $0.143-0.18$ and therefore it appears that all the four complexes have two thiolate S-atoms possibly in the cis-geometry [32]. As the two $\mathrm{O}$-atoms of the acetylacetonato ligand should be in cis-configuration, it is expected that the remainder of the two $\mathrm{N}$-atoms of the two thiohydrazide ligands will also be in cis-geometry. This conclusion was further supported by the optimized structure derived from DFT study (vide infra). Hyperfine coupling was evident in the EPR spectra for all the four complexes due to the presence of two $\mathrm{N}(I=1)$ atoms. However, the spectra could not be satisfactorily simulated because of large line width arising from $\mathrm{H}$-strain.

3.5. Electrochemistry. Cyclic voltammograms of the thiohydrazide ligands showed a prominent reduction peak between $-0.62 \mathrm{~V}$ and $-0.96 \mathrm{~V}$. The position of the peak however depends on the aromatic group of the ligand. The peaks are tabulated in Table 2.

The corresponding cathodic peaks shift by about $-0.1 \mathrm{~V}$ in the thiobenzhydrazido, 2-hydroxythiobenzhydrazido, and thiophen-2-thiohydrazido iron complexes. However a reverse order is obtained in the furan-2-thiohydrazido complex. These peaks may be designated as ligand based reduction. The ligand-based reduction is irreversible and no corresponding anodic peaks are observed. In all the ligands an irreversible oxidation peak is also observed between $0.8 \mathrm{~V}$ and $1.0 \mathrm{~V}$. The corresponding reduction peaks were not found. These anodic peaks also shifted towards the negative side in the iron complexes and these oxidations may be regarded as ligand-based oxidation. In all the iron complexes a new quasireversible reduction peak at $\sim 0.25 \mathrm{~V}$ and a corresponding oxidation peak at $\sim 0.39 \mathrm{~V}$ were observed. This may be regarded as a metal based quasireversible oxidation, that is, $\mathrm{Fe}(\mathrm{II})$ to $\mathrm{Fe}(\mathrm{III})$. The mother compound, ferric acetylacetonate, shows a reversible reduction peak with $E_{1 / 2}$ value of $-0.61 \mathrm{~V}$ and an irreversible oxidation peak at $1.7 \mathrm{~V}$ [33]. The deviation of acetylacetonatobisthiohydrazidoiron(III) complex from that of the trisacetylacetonatoiron(III) complex may be explained from the fact that the former is a low spin complex while the latter is a high spin complex. The low spin octahedral ferric complexes are characterized by ill-defined cyclic voltammograms $[34,35]$. Cyclic voltammograms 


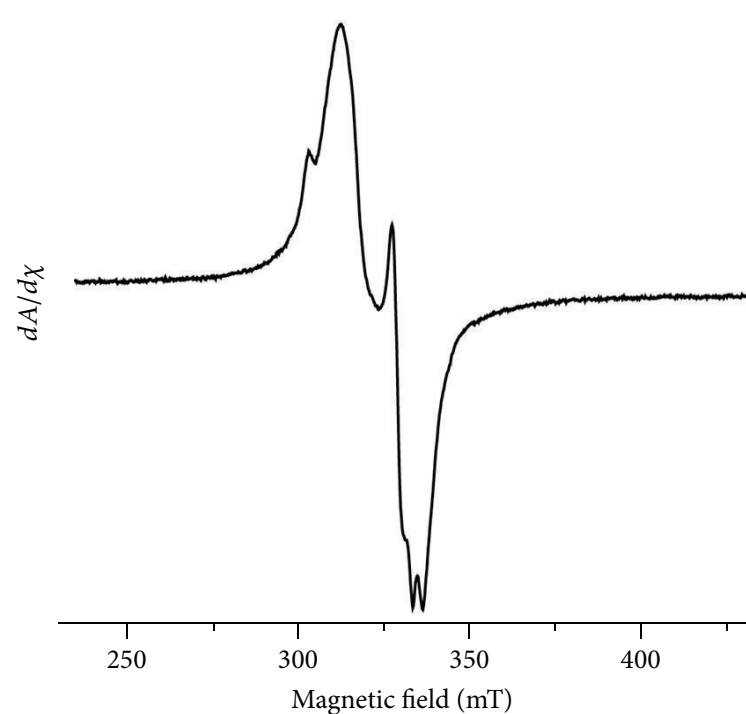

(a)

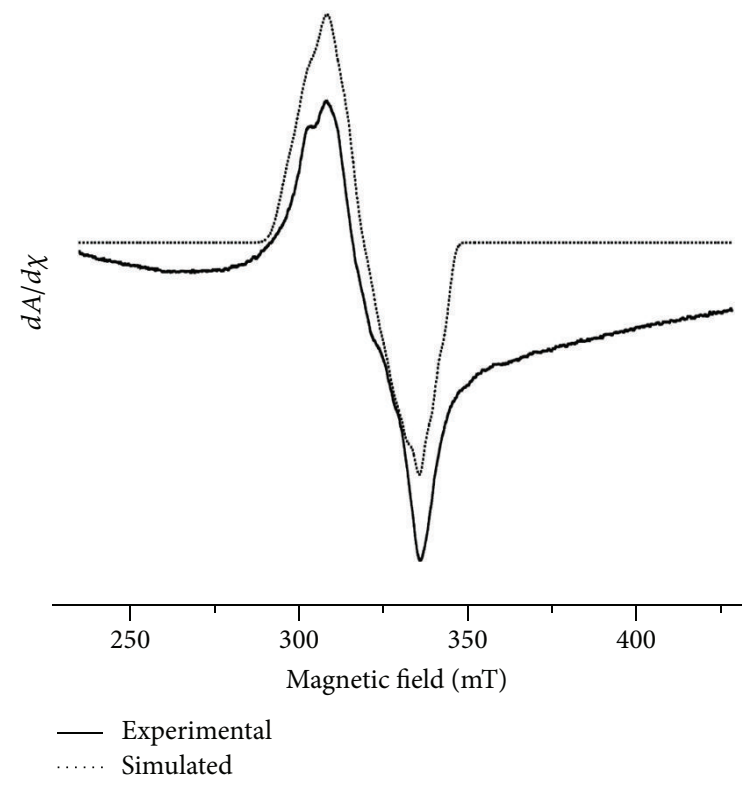

(c)

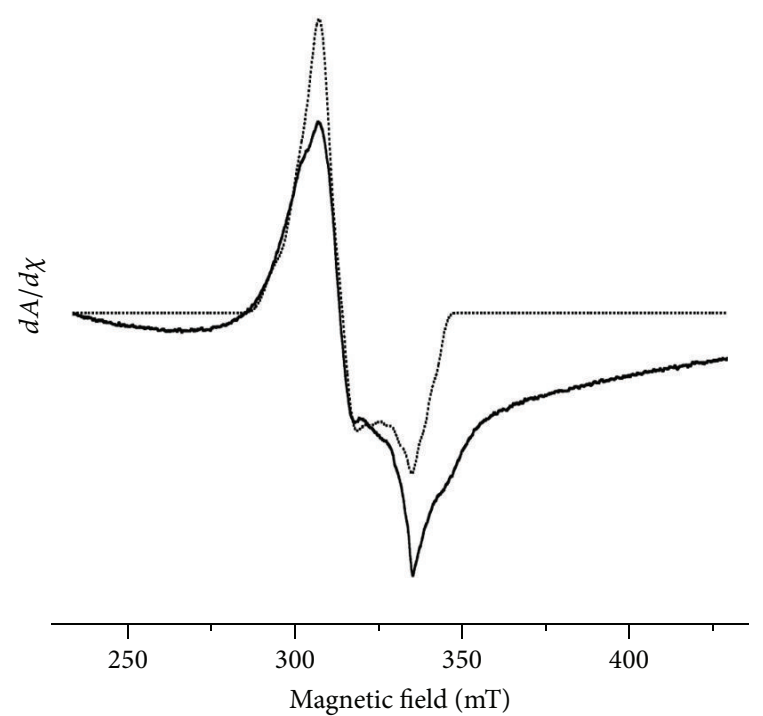

Experimental Simulated

(b)

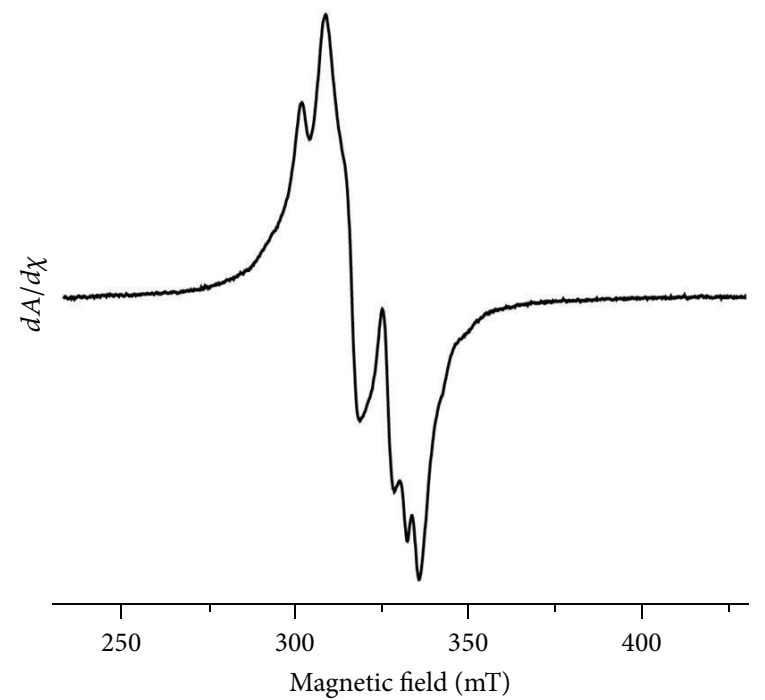

(d)

Figure 2: Continuous wave (CW) X-band EPR spectra for (a) Fe(acac)(tbh) $)_{2}$, (b) Fe(acac)(htbh) $)_{2}$, (c) Fe(acac)(fth) $)_{2}$, and (d) Fe(acac)(tth) in DMSO at $10 \mathrm{~K}$. The simulated spectra for the complexes are shown as black dotted lines, while the original spectra are shown as solid black lines. Spectrometer settings: microwave frequency: $9.43 \mathrm{GHz}$; microwave power: $10 \mathrm{~mW}$; modulation frequency: $100 \mathrm{kHz}$, modulation amplitude: $2 \mathrm{G}$.

of thiohydrazide ligands and their corresponding acetylacetonatobisthiohydrazidoiron(III) complexes are available in Supplementary Material available online at http://dx.doi .org/10.1155/2014/580232.

3.6. Antibacterial Activity. The result of E. coli growth inhibition study of all the aromatic thiohydrazide ligands and their complexes of iron(III) are presented in the graphical diagram in Figure 3. It may be mentioned that $\left[\mathrm{Fe}(\mathrm{acac}) \mathrm{L}_{2}\right]$ complexes are stable in DMSO for seven days, because they exhibited same antibacterial activity in DMSO solution for that period. From the figure it is evident that all the aromatic thiohydrazide complexes of iron(III) show antibacterial activity. Moreover it can be concluded that $\mathrm{H}(\mathrm{tbh})$ and $\mathrm{H}(\mathrm{tth})$ complexes of iron(III) show marginally better antibacterial effect compared to the other complexes of thiohydrazide ligand. Extrapolation of the curve to zero percent growth 


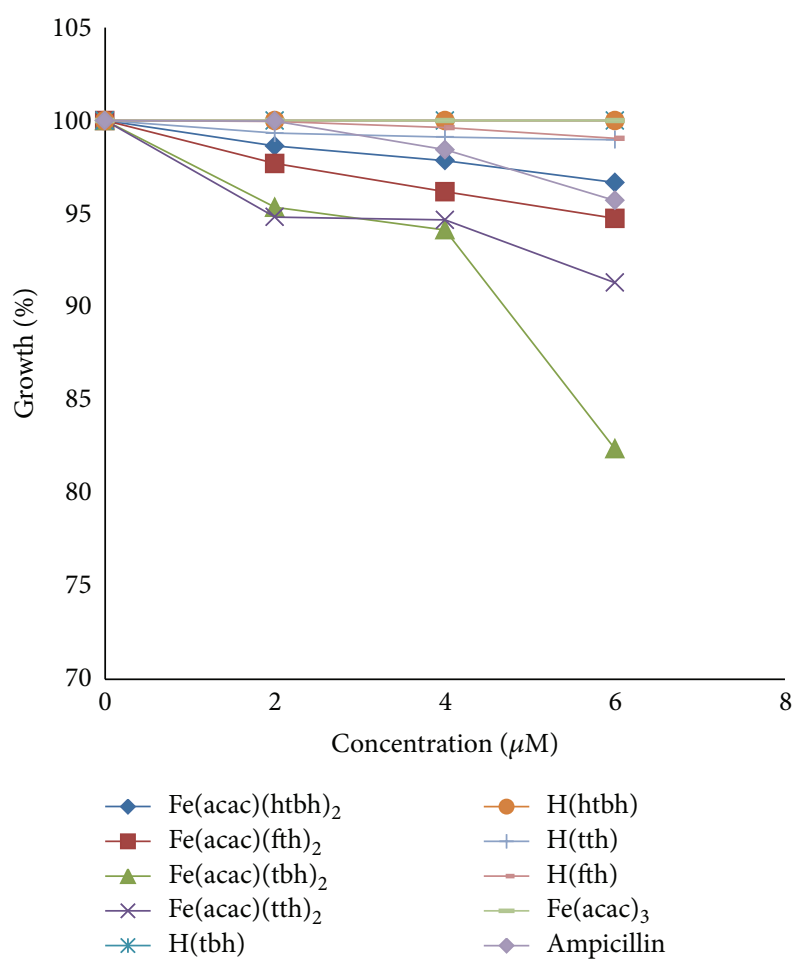

FIGURE 3: Effect of Ampicillin, ligands, and iron thiohydrazides on the growth of E. coli.

TABLE 3: Minimum inhibitory concentrations (MIC) of Ampicillin, ligands, and iron thiohydrazide complexes.

\begin{tabular}{lc}
\hline Compound & MIC $(\mu \mathrm{M})$ \\
\hline$\left[\mathrm{Fe}(\mathrm{acac})(\mathrm{tbh})_{2}\right]$ & 10.34 \\
{$\left[\mathrm{Fe}(\mathrm{acac})(\mathrm{htbh})_{2}\right]$} & 17.81 \\
{$\left[\mathrm{Fe}(\mathrm{acac})(\mathrm{tth})_{2}\right]$} & 13.88 \\
{$\left[\mathrm{Fe}(\mathrm{acac})(\mathrm{fth})_{2}\right]$} & 16.44 \\
$\mathrm{H}(\mathrm{tbh})$ & Greater than 100 \\
$\mathrm{H}(\mathrm{htbh})$ & Greater than 100 \\
$\mathrm{H}(\mathrm{tth})$ & 45.65 \\
$\mathrm{H}(\mathrm{fth})$ & 47.39 \\
Ampicillin & 19.8 \\
\hline
\end{tabular}

gives the minimum volume of the stock solution, required for total inhibition of the growth of the microorganism. From the volume of the stock solution minimum inhibitory concentration (MIC) is calculated and shown in Table 3. It has been observed that the MIC values of all the aromatic thiohydrazide complexes of iron(III) are less than that of a well-known antibiotic Ampicillin which has a MIC value of $19.8 \mu \mathrm{M}$.

Antibacterial study against $E$. coli strain shows that all the iron(III) complexes of aromatic thiohydrazides completely inhibit the growth of the microorganism with the maximum value of $17.8 \mu \mathrm{M}$ concentration in vitro. Further studies on animal and fungus model may prove the compounds as useful drug. Effect of $\mathrm{Fe}(\mathrm{acac})_{3}$ for the inhibition of the growth of

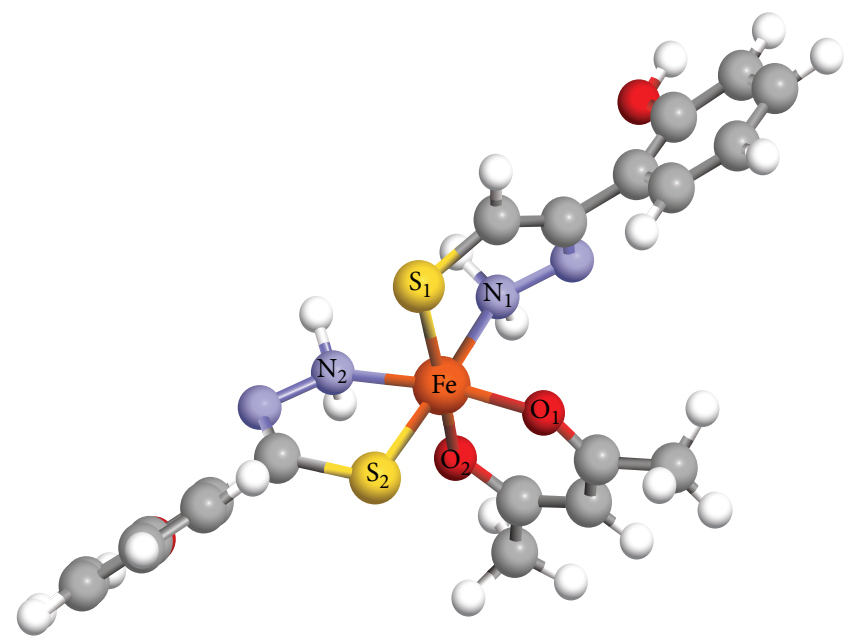

FIGURE 4: Optimized structure of acetylacetonato-bis-2-hydroxythiobenzhydrazidoiron(III) [Fe(acac)(htbh) ${ }_{2}$ ]. Color scheme: Fe: orange; S: yellow; O: red; N: purple; C: grey; and H: white.

E. coli was also studied, but the growth curve runs parallel to the $X$ axis, indicating no antibacterial effect.

\section{Molecular Modeling}

DFT calculations for acetylacetonatobis-2-hydroxythiobenzhydrazidoiron(III) $\left[\mathrm{Fe}(\mathrm{acac})(\mathrm{htbh})_{2}\right]$ were performed with NWChem 6.1 program package and geometry optimization was done with UB3LYP functional. The basis set $6-31 G^{*}$ was used for nonmetal atoms while Ahlrichs' VTZ (valence triple- $\xi$ ) basis set was used for Fe atom [36]. Since the spectral characteristics and magnetic properties of all other complexes are analogous, no attempt has been made for structure optimization for those other complexes. The optimized structure of the complex exhibited an octahedral iron(III) ion in a hexa-coordinated ligand environment containing two sets of nitrogen and sulfur atoms from two identical uninegative 2-hydroxythiobenzhydrazido ligand and two oxygen atoms from the remaining acetylacetonato ligand (Figure 4). Selected bond angles and bond distances for the optimized structure are shown in Table 4 . The Cartesian coordinates of all the atoms constituting the optimized structure are provided as Table S1 of the Supplementary Material. Surface plots of HOMO and LUMO with their energies are presented in Figure 5. Despite the octahedral symmetry, the Fe center possesses high rhombic distortion. Two nitrogen and two sulfur atoms as donor in the complex are in relative cisposition. High rhombic distortion is in conformity with large $V / \lambda$ and low $\left(g_{\max }-g_{\min }\right)$ values observed in the EPR spectra as shown in Table 1. Calculations of atomic spin population have demonstrated the presence of the unpaired electron mostly on the Fe atom as expected. However, significant amount of unpaired electron spin was noticed over one of the thiobenzhydrazido ligands (on sulfur, hydrazine $\mathrm{N}$, and C atoms) (Table S2, Supplementary Material).

The calculations also indicated that both the HOMO and LUMO orbitals are dominated by Fe d orbitals. The calculated 
TABLE 4: Selected bond lengths $(\AA)$ and bond angles $\left(^{\circ}\right)$ for the optimized structure of $\left[\mathrm{Fe}(\mathrm{acac})(\mathrm{htbh})_{2}\right]$.

(a) Bond lengths $(\AA)$

\begin{tabular}{llll}
\hline $\mathrm{Fe}-\mathrm{O}_{1}$ & 1.940 & $\mathrm{Fe}-\mathrm{N}_{2}$ & 2.029 \\
$\mathrm{Fe}-\mathrm{O}_{2}$ & 1.973 & $\mathrm{Fe}-\mathrm{S}_{1}$ & 2.223 \\
$\mathrm{Fe}-\mathrm{N}_{1}$ & 2.105 & $\mathrm{Fe}-\mathrm{S}_{2}$ & 2.295 \\
\hline
\end{tabular}

(b) Bond angles $\left({ }^{\circ}\right)$

\begin{tabular}{llllllll}
\hline $\mathrm{O}_{1}-\mathrm{Fe}-\mathrm{O}_{2}$ & 93.61 & $\mathrm{O}_{1}-\mathrm{Fe}-\mathrm{N}_{2}$ & 172.36 & $\mathrm{O}_{1}-\mathrm{Fe}-\mathrm{S}_{1}$ & 93.51 & $\mathrm{~N}_{1}-\mathrm{Fe}-\mathrm{S}_{1}$ & 85.47 \\
$\mathrm{~N}_{1}-\mathrm{Fe}-\mathrm{N}_{2}$ & 94.69 & $\mathrm{O}_{2}-\mathrm{Fe}-\mathrm{S}_{1}$ & 168.90 & $\mathrm{O}_{1}-\mathrm{Fe}-\mathrm{N}_{1}$ & 89.72 & $\mathrm{~N}_{2}-\mathrm{Fe}-\mathrm{S}_{2}$ & 83.25 \\
$\mathrm{~S}_{1}-\mathrm{Fe}-\mathrm{S}_{2}$ & 93.33 & $\mathrm{~N}_{1}-\mathrm{Fe}-\mathrm{S}_{2}$ & 177.59 & $\mathrm{O}_{2}-\mathrm{Fe}-\mathrm{S}_{2}$ & 94.87 & & \\
\hline
\end{tabular}

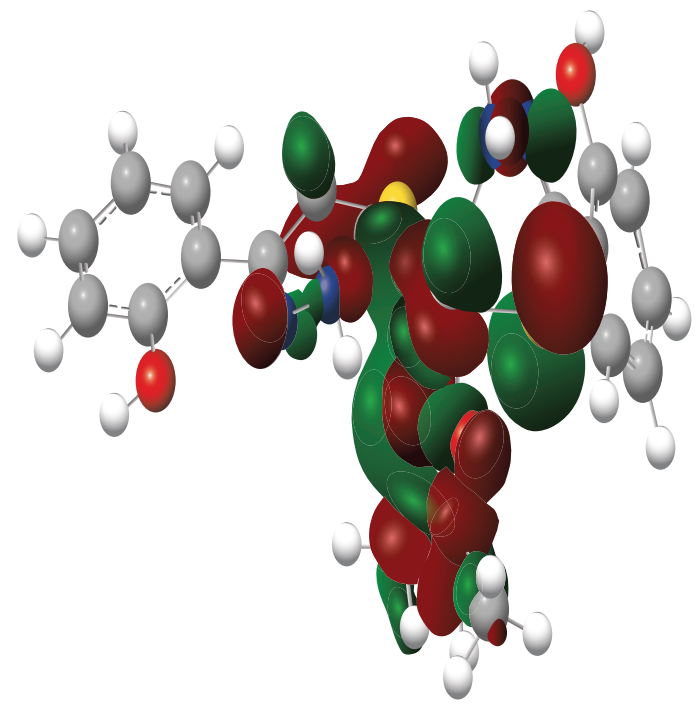

(a)

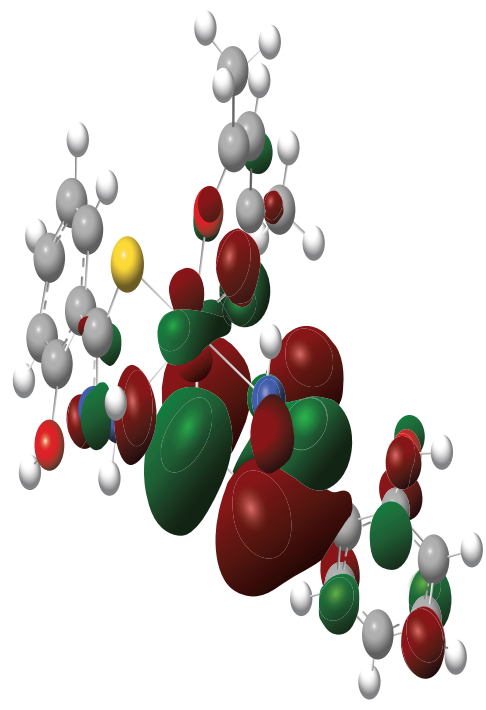

(b)

Figure 5: (a) Surface plot of HOMO of $\left[\mathrm{Fe}(\mathrm{acac})(\mathrm{htbh})_{2}\right], E=-0.2635703$ a.u.; (b) Surface plot of LUMO of $\left[\mathrm{Fe}(\mathrm{acac})(\mathrm{htbh})_{2}\right], E=$ -0.2121149 a.u.

energy difference between these two orbitals $\left(11293 \mathrm{~cm}^{-1}\right)$ matched well with the experimental signal we observed in the electronic spectra for this complex $\left(11124 \mathrm{~cm}^{-1}\right.$ or $\left.899 \mathrm{~nm}\right)$. So we can predict this transition as a predominantly $\mathrm{d}-\mathrm{d}$ transition.

\section{Conclusion}

Relatively rare, low spin $\left(d^{5}, S=1 / 2\right)$ paramagnetic mixed ligand complexes of octahedral iron(III) have been synthesized from $\mathrm{Fe}(\mathrm{acac})_{3}$ by displacing two acetylacetonate ligands with four different bidentate thiohydrazide ligands. Spectroscopic evidences suggest the presence of high rhombic distortion in the otherwise octahedral geometry around Fe center. DFT calculations on $\mathrm{Fe}$ (acac)(htbh) ${ }_{2}$ showed a closely lying HOMO and LUMO, separated by NIR region energy difference, where both the MOs have predominantly metal d-orbital character. The calculated energy difference was in close agreement with $\mathrm{d}$ - $\mathrm{d}$ transition band as observed in the electronic spectra for the complex. Since the spectral features of all the complexes are similar in nature, all other complexes should have similar structure. All the iron thiohydrazide complexes demonstrated higher in vitro bactericidal effects compared to those of the corresponding free ligands.

\section{Conflict of Interests}

The authors declare that there is no conflict of interests regarding the publication of this paper.

\section{Acknowledgments}

The authors thank Professor P. P. Kundu, of the Department of Polymer Science and Technology, University of Calcutta, for providing some instrumental facilities of his laboratory. They express their gratitude to Bojana Ginovska-Pangovska, Scientist, Pacific Northwest National Laboratory, for providing computational assistance and helpful discussion. Financial assistance received from UGC, New Delhi, and Higher Education Department, Government of West Bengal, is gratefully acknowledged. 


\section{References}

[1] M. J. M. Campbell, “Transition metal complexes of thiosemicarbazide and thiosemicarbazones," Coordination Chemistry Reviews, vol. 15, pp. 279-319, 1975.

[2] S. Padhye and G. B. Kauffman, "Transition metal complexes of semicarbazones and thiosemicarbazones," Coordination Chemistry Reviews, vol. 63, pp. 127-160, 1985.

[3] D. X. West, S. B. Padhye, and P. B. Sonawane, "Structural and physical correlations in the biological properties of transition metal heterocyclic thiosemicarbazone and Salkyldithiocarbazate complexes," in Complex Chemistry, vol. 76 of Structure and Bonding, pp. 1-50, 1991.

[4] D. X. West, A. E. Liberta, S. B. Padhye et al., "Thiosemicarbazone complexes of copper(II): structural and biological studies," Coordination Chemistry Reviews, vol. 123, no. 1-2, pp. 49-71, 1993.

[5] J. S. Casas, M. S. Garcia-Tasende, and J. Sordo, "Main group metal complexes of semicarbazones and thiosemicarbazones. A structural review," Coordination Chemistry Reviews, vol. 209, pp. 197-201, 2000.

[6] A. A. El-Asmy, N. M. El-Metwally, and G. A. Al-Hazmi, "Chelation and analytical application of thiosemicarbazides toward Platinum(IV) ions," Transition Metal Chemistry, vol. 31, no. 5, pp. 673-688, 2006.

[7] M. T. Martinez Aguilar and J. M. Cano Pavon, “2benzoylpyridine-4-phenyl-3-thiosemicarbazone as an analytical reagent for spectrophotometric determination of iron," Mikrochimica Acta, vol. 68, no. 5-6, pp. 631-637, 1977.

[8] N. Uehara, K. Morimoto, and Y. Shijo, "Separation and determination of metal ions as picolinaldehyde 4-Phenyl3-thiosemicarbazone chelates by reversed-phase highperformance liquid chromatography," The Analyst, vol. 117, no. 6, pp. 977-979, 1992.

[9] M. Y. Khuhawar and G. M. Arain, "Liquid chromatographic determination of vanadium in petroleum oils and mineral ore samples using 2-acetylpyridne-4-phenyl-3-thiosemicarbazone as derivatizing reagent," Talanta, vol. 68, no. 3, pp. 535-541, 2006.

[10] A. P. Nair and C. Jeyasulan, "Spectrophotometric dteremination of $\mathrm{Cu}(\mathrm{II})$ and $\mathrm{Ni}$ (II) using 4-phenyl-3-thiosemicarbazone of 2hydroxy-4-n-propoxy-5-bromoacetophenone (HnPBAPT) as analytical reagent," American International Journal of Research in Formal, Applied \& Natural Sciences, vol. 3, pp. 46-50, 2013.

[11] H. Beraldo and D. Gambino, "Wide pharmacological versatility of semicarbazones, thiosemicarbazones and their metal complexes," Mini Reviews in Medicinal Chemistry, vol. 4, pp. 159165, 2004.

[12] V. Raj, V. Kumar, and S. Kumar, "Review on CNS activity of thiosemicarbazone derivatives," International Journal of Pharmacy and Integrated Life Sciences, vol. 1, pp. 30-45, 2013.

[13] D. J. Bauer, L. St. Vincent, C. H. Kempe, and A. W. Downe, "In England now," The Lancet, vol. 281, no. 7279, pp. 494-495, 1963.

[14] T. Rosu, E. Pahontu, S. Pasculescu et al., "Synthesis, characterization antibacterial and antiproliferative activity of novel $\mathrm{Cu}(\mathrm{II})$ and $\mathrm{Pd}(\mathrm{II})$ complexes with 2-hydroxy-8R-tricyclo[7.3.1.0.2,7]tridecane-13-one thiosemicarbazone," European Journal of Medicinal Chemistry, vol. 45, no. 4, pp. 1627-1634, 2010.

[15] E. W. Y. Tido, E. J. M. Vertelman, A. Meetsma, and P. J. van Koningsbruggen, "Crystal structure and magnetic behaviour of a five-coordinate iron(III) complex of pyridoxal-4methylthiosemicarbazone," Inorganica Chimica Acta, vol. 360, no. 13, pp. 3896-3902, 2007.

[16] J. P. Scovill, D. L. Klayman, and C. F. Franchino, "2Acetylpyridine thiosemicarbazones. 4. Complexes with transition metals as antimalarial and antileukemic agents," Journal of Medicinal Chemistry, vol. 25, no. 10, pp. 1261-1264, 1982.

[17] L. A. Saryan, K. Mailer, C. Krishnamurti, W. Antholine, and D. H. Petering, "Interaction of 2-formylpyridine thiosemicarbazonato copper (II) with ehrlich ascites tumor cells," Biochemical Pharmacology, vol. 30, no. 12, pp. 1595-1604, 1981.

[18] L. A. Saryan, E. Ankel, C. Krishnamurti, D. H. Petering, and H. Elford, "Comparative cytotoxic and biochemical effects of ligands and metal complexes of $\alpha$-N-heterocyclic carboxaldehyde thiosemicarbazones," Journal of Medicinal Chemistry, vol. 22, no. 10, pp. 1218-1221, 1979.

[19] M. X. Li, J. Zhou, H. Zhao, C.-L. Chen, and J.-P. Wang, "Iron(III) complex of 2-acetylpyrazine thiosemicarbazone: synthesis, spectral characterization, structural studies and antitumoral activity," Journal of Coordination Chemistry, vol. 62, no. 9, pp. 1423-1429, 2009.

[20] P. Basak, S. Gangopadhyay, S. De, M. G. B. Drew, and P. K. Gangopadhyay, "Cobalt(III) complexes of some aromatic thiohydrazides-synthesis, characterization and structure," Inorganica Chimica Acta, vol. 363, no. 7, pp. 1495-1499, 2010.

[21] M. K. Chaudhuri and S. K. Ghosh, "Notes. Novel synthesis of tris(acetylacetonato)iron(III)," Journal of the Chemical Society, Dalton Transactions, no. 4, pp. 839-840, 1983.

[22] S. Stoll and A. Schweiger, "EasySpin, a comprehensive software package for spectral simulation and analysis in EPR," Journal of Magnetic Resonance, vol. 178, no. 1, pp. 42-55, 2006.

[23] Brock Biology of Microorganisms, vol. 157, Prentice Hall, New York, NY, USA, 8th edition, 1997.

[24] S. K. Chattopadhyay and S. Ghosh, "A study of Ru(II) complexes of some selected NS donors," Inorganica Chimica Acta, vol. 131, no. 1, pp. 15-20, 1987.

[25] S. A. Richert, P. K. S. Tsang, and D. T. Sawyer, "Ligandcentered redox processes for manganese, iron and cobalt, $\mathrm{MnL}_{3}, \mathrm{FeL}_{3}$, and $\mathrm{CoL}_{3}$, complexes ( $\mathrm{L}=$ acetylacetonate, 8-quinolinate, picolinate, 2,2'-bipyridyl, 1,10-phenanthroline) and for their tetrakis(2,6-dichlorophenyl)porphinato complexes[M(Por)]," Inorganic Chemistry, vol. 28, pp. 2471-2475, 1989.

[26] J. García-Tojal, J. L. Pizarro, L. Lezama, M. I. Arriortua, and T. Rojo, "Spectroscopic and magnetic properties of the pyridine-2-carbaldehyde thiosemicarbazonateiron(III) complexes: $\left[\mathrm{Fe}\left(\mathrm{C}_{7} \mathrm{H}_{7} \mathrm{~N}_{4} \mathrm{~S}\right)_{2}\right] \mathrm{X} \cdot \eta \mathrm{H}_{2} \mathrm{O}\left(\mathrm{X}=\mathrm{Cl}, \mathrm{ClO}_{4}, \mathrm{NO}_{3}, \mathrm{PF}_{6}\right)$. Crystal structure of the hexafluorophosphate compound," Inorganica Chimica Acta, vol. 278, no. 2, pp. 150-158, 1998.

[27] M. Cañadas, E. López-Torres, A. Martínez-Arias, M. Antonia Mendiola, and M. Teresa Sevilla, "Spectroscopic and electrochemical properties of nickel(II), iron(III) and cobalt(II) complexes with benzilbisthiosemicarbazone-importance of working conditions and the metal salt used in the final complex," Polyhedron, vol. 19, no. 18-19, pp. 2059-2068, 2000.

[28] R. C. Chikate and S. B. Padhye, "Transition metal quinonethiosemicarbazone complexes 3: Spectroscopic characterizations of spin-mixed iron (III) of naphthoquinone-thiosemicarbazones," Spectrochimica Acta A: Molecular and Biomolecular Spectroscopy, vol. 66, no. 4-5, pp. 1091-1096, 2007. 
[29] K. Nakamoto, Infrared and Raman Spectra of Inorganic and Coordination Compounds, John Wiley \& Sons, New York, NY, USA, 4th edition, 1986.

[30] C. P. S. Taylor, "The EPR of low spin heme complexes Relation of the $\tau_{2 \mathrm{~g}}$ hole model to the directional properties of the $g$ tensor, and a new method for calculating the ligand field parameters," Biochimica et Biophysica Acta (BBA)_Protein Structure, vol. 491, no. 1, pp. 137-149, 1977.

[31] T. I. Bohan, "Analysis of low-spin ESR spectra of ferric heme proteins: a re examination," Journal of Magnetic Resonance, vol. 26, no. 1, pp. 109-118, 1977.

[32] J. C. Noveron, R. Herradora, M. M. Olmstead, and P. K. Mascharak, "Low-spin iron(III) complexes with N,S coordination: Syntheses, structures, and properties of bis(N-2-mercaptophenyl-2' -pyridylmethyleniminato)iron(III) tetraphenylborate and bis(N-2-mercapto-2-methylpropyl-2' -pyridylmethyleniminato)iron(III) tetraphenylborate," Inorganica Chimica Acta, vol. 285, no. 2, pp. 269-276, 1999.

[33] J. H. Tocher and J. P. Fackler Jr., "Electrochemical investigations of several transition metal tris(acetylacetonate) complexes," Inorganica Chimica Acta, vol. 102, no. 2, pp. 211-215, 1985.

[34] L. D. Field, A. V. George, and T. W. Hambley, "Synthesis and structure of dichlorodi-[1,2-bis(dimethylphosphino)ethane] iron(III) tetrachloroferrate(III), $\left[\mathrm{Fe}(\mathrm{DMPE})_{2} \mathrm{Cl}_{2}\right]^{+}\left[\mathrm{FeCl}_{4}\right]^{-}$,", Polyhedron, vol. 9, no. 17, pp. 2139-2141, 1990.

[35] C. Bianchini, F. Laschi, D. Masi et al., "A family of stable iron(I) $\sigma$-alkynyl complexes. Synthesis, characterization, structure, and electron-transfer chemistry," Journal of the American Chemical Society, vol. 115, no. 7, pp. 2723-2730, 1993.

[36] A. A. Jarzecki, A. D. Anbar, and T. G. Spiro, "DFT analysis of $\mathrm{Fe}(\mathrm{H} 2 \mathrm{O}) 63+$ and $\mathrm{Fe}(\mathrm{H} 2 \mathrm{O}) 62+$ structure and vibrations; implications for isotope fractionation," The Journal of Physical Chemistry, vol. 108, no. 14, pp. 2726-2732, 2004. 

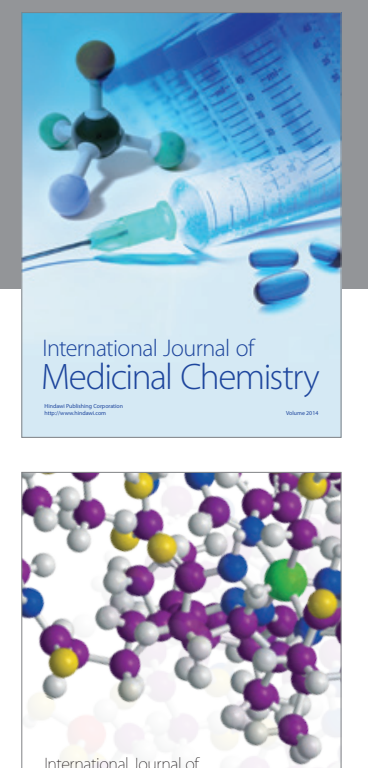

\section{Carbohydrate} Chemistry

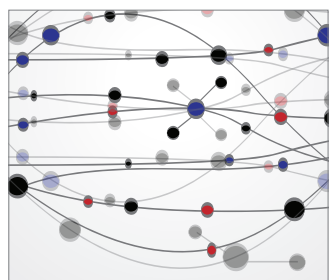

The Scientific World Journal
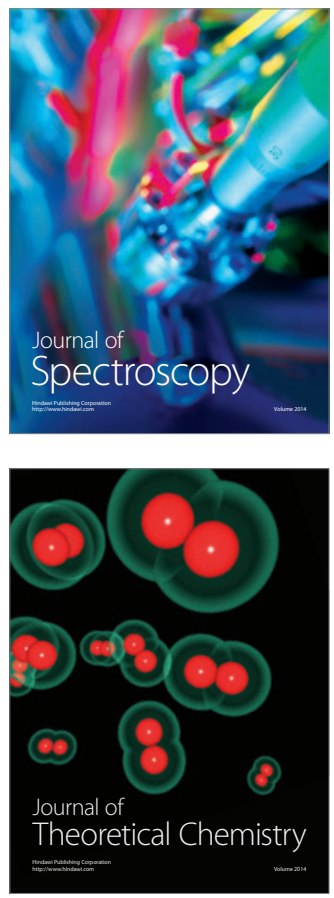
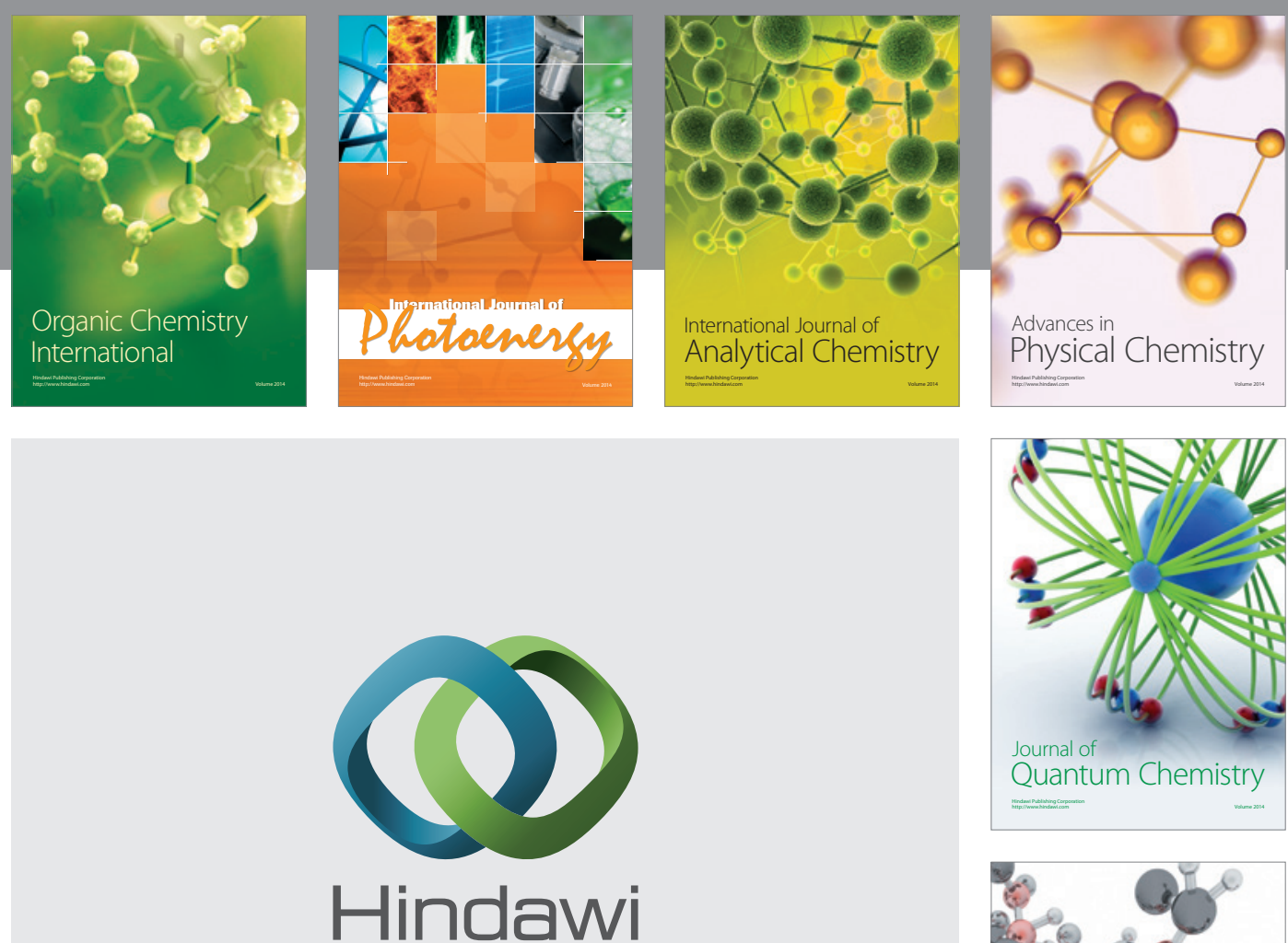

Submit your manuscripts at

http://www.hindawi.com

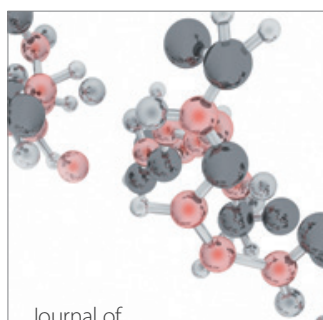

Analytical Methods

in Chemistry

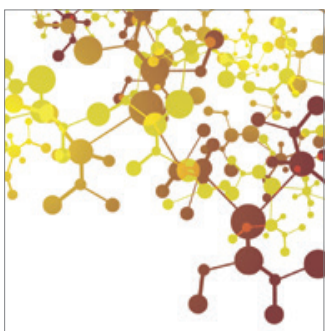

Journal of

Applied Chemistry

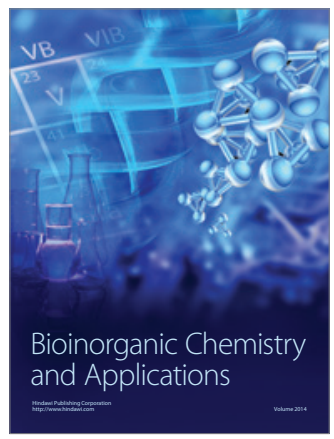

Inorganic Chemistry
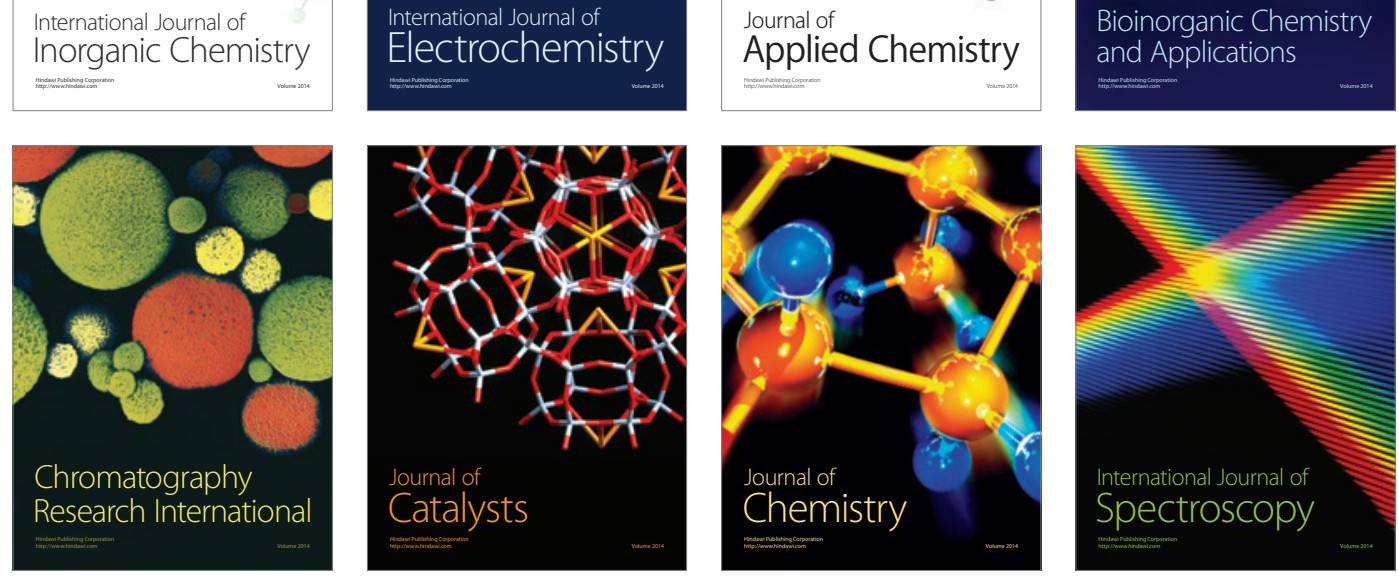